\title{
A Study of Maternal Breast Feeding Issues during Early Postnatal Days
}

\author{
Shreedhara Avabratha K. ${ }^{a^{*}}$, Sweta Shanbhag ${ }^{\mathrm{b}}$, Rilna Clara Joseph ${ }^{\mathrm{b}}$, \\ Varadaraj Shenoy K. ${ }^{\mathrm{b}}$ \\ ${ }^{a}$ Professor, Department of Pediatrics, Father Muller Medical College, Mangalore, Karnataka, India. \\ ${ }^{b}$ Father Muller Medical College, Mangalore, Karnataka, India. \\ Received 18 April 2020; Accepted 09 October 2020
}

\begin{abstract}
Background: The success in breast-feeding is dependent on early initiation and effective management of breast feeding problems during early postnatal days. Objectives: To identify breast feeding problems and their etiologies during early postnatal days until discharge from hospital. Methodology: Descriptive study done in a medical college hospital. One hundred and twenty mothers in early postnatal days were enrolled in the study. Sick mothers, sick neonates admitted in NICU for $>24$ hours and where breast-feeding was contraindicated were excluded. Data was collected by direct interview with the mother by the investigators and were entered in the proforma. The questionnaire contained general information of the mothers, self-reported and observed problems about breast feeding. The first interview was carried out within 12 hours of delivery after taking informed consent. Follow up interviews were done on 24 hourly basis until discharge. Data was analyzed statistically. Results: Mothers were aged between 22 to 40 years with more than half in 26-30 years range. Majority were homemakers and educated up to high school. 31(25.8\%) were primi mothers. 64(53\%) had vaginal and $56(47 \%)$ had caesarean deliveries. $61.6 \%$ of the mothers knew about colostrum and its benefits. Most $(98.3 \%)$ of the mothers felt that there is a need for education about breast-feeding. Majority had initiated breast feeds within an hour or at least within 4 hours (LSCS mothers). Insufficiency of milk and problems with latching, positioning and sucking were some of the problems noted. Though most of the problems were resolved before discharge, few persisted until discharge. Perceived milk insufficiency, latching problems and breast problems were higher in primi and found to be statistically significant. Objective problems like poor positioning, sucking etc were higher among primi and caesarean mothers. Even problems that remained at discharge were also more among them. Conclusions: Most common problems were positioning, emphasizing the need for teaching/training. Primi and delivery by LSCS were found to have higher feeding problems emphasizing the need to focus on these high risk groups.
\end{abstract}

Keywords: Breast Feeding; Problems; Postnatal Days.

\section{Introduction}

Human milk is the most appropriate milk for the baby. Breast milk though considered to be natural, breast feeding does not come naturally to all the mothers. Successful breast feeding requires proper education and needs to be learnt.

Breast feeding has many benefits to the baby, mother as well as the nation. Exclusive breast feeding is recommended for the initial 6 months, by AAP and the WHO [1]. However exclusive breastfeeding, knowledge and feeding practices are found to be suboptimal among rural north Indian women [2]. NFHS - 4 data shows that only $56 \%$ of mothers exclusively breast feed up to 6 months in India [3]. The reason for this may vary from lack of knowledge to problems in breast or nipple.

* Corresponding author: shreedharkdr@fathermuller.in

$>$ This is an open access article under the CC-BY license (https://creativecommons.org/licenses/by/4.0/).

(C) Authors retain all copyrights. 
The success in breast feeding is dependent on early initiation and effective management of breast feeding problems during initial postnatal days. There may be regional variations too. Hence this study was taken up to identify the factors to be addressed in postnatal mothers about breast feeding in early postnatal days. The objective of the study was to identify the breast feeding problems and their etiologies during early postnatal days until discharge from hospital and also to evaluate the need for educating mothers.

\section{Material and methods}

This is a descriptive study. One hundred and twenty mothers in early postnatal days who were in the wards of a medical college hospital were randomly enrolled in the study. Data was collected by direct interview with the mother by the investigators and were entered in the proforma. A pretested proforma validated for content was used. The questionnaire contained general information of the mothers and mode of delivery. It also included self-reported problems about breast-feeding. Many of these mothers were observed during feeding to confirm the problems whenever needed. These documented problems were also entered into the proforma. Mothers of late preterm (34-37 weeks) and term (>37weeks) babies delivered in the hospital were included in the study. Sick mothers, Sick neonates admitted in NICU for $>24$ hours and where breast-feeding was contraindicated were the exclusion criteria.

The first interview was carried out within 12 hours of delivery after taking informed consent. Follow up interviews were done on 24 hourly basis until discharge (At least 3 visits). Institutional Ethics Committee (IEC) | Public Health Foundation of India approved the study. Statistical analysis: Data are presented in frequency and percentages. Descriptive statistics-tables, figures, proportion. Inferential statistics- $\mathrm{X}^{2}$ test for bivariate analysis. Odds ratio with 95\% CI to provide degree of association are used.

\section{Results}

A total of 120 mothers were interviewed. They were aged between 22 to 40 years with more than half in 26-30 years range. Majority were homemakers and educated up to high school (Table 1).

Table 1. Demographic characteristics

\begin{tabular}{|c|c|c|c|c|c|}
\hline Sl no. & Variables & Categories & Number & Percentage & Mean \pm SD \\
\hline \multirow{4}{*}{1} & \multirow{4}{*}{ Age } & $20-25 \mathrm{yrs}$ & 41 & $34.1 \%$ & \multirow{4}{*}{$26.9 \pm 3.61$} \\
\hline & & $26-30 \mathrm{yrs}$ & 64 & $53.3 \%$ & \\
\hline & & $31-35$ yrs & 12 & $10 \%$ & \\
\hline & & $>35 \mathrm{yrs}$ & 3 & $2.5 \%$ & \\
\hline \multirow{5}{*}{2} & \multirow{5}{*}{ Occupation } & Homemaker & 96 & $80 \%$ & \\
\hline & & Daily wage/manual labourer & 10 & $8.3 \%$ & \\
\hline & & Skilled & 4 & $3.3 \%$ & \\
\hline & & Clerical & 5 & $4.1 \%$ & \\
\hline & & Professional & 5 & $4.1 \%$ & \\
\hline \multirow{4}{*}{3} & \multirow{4}{*}{ Education } & Primary & 40 & $33.3 \%$ & \\
\hline & & High school & 45 & $37.5 \%$ & \\
\hline & & Preuniversity & 23 & $19.1 \%$ & \\
\hline & & Degree & 12 & $10 \%$ & \\
\hline
\end{tabular}

$31(25.8 \%)$ were primi mothers. $64(53 \%)$ had vaginal and $56(47 \%)$ underwent caesarean deliveries. $48 \%$ of the babies were girls and the remaining were boys. All the mothers had received antenatal care. Majority (92.5\%) had some kind of prior information about breast feeding largely obtained from family/friends. $61.6 \%$ of the mothers knew about colostrum and its benefits. However, $98.3 \%$ of the mothers felt that there is a need for education about breastfeeding. Most of the mothers had initiated breast feeds within an hour or at least within 4 hours (LSCS mothers).

Most of the mothers had one or the other perceived breast feeding problems. The problems reported (Table 2) by mothers varied from insufficiency of milk to difficulty in holding the baby. Breast related problems like pain, retraction of nipple, engorgement of breast were reported in $38.3 \%$. Problems related to mother like pain of episiotomy, caesarean also contributed to breast feeding issues. 
Table 2. Breastfeeding problems - reported

\begin{tabular}{|c|c|c|c|c|}
\hline Sl no. & Variables & Response & Number & Percentage \\
\hline \multirow{2}{*}{1} & \multirow{2}{*}{ Insufficiency of milk } & Yes & 35 & $29.1 \%$ \\
\hline & & No & 85 & $70.9 \%$ \\
\hline \multirow{2}{*}{2} & \multirow{2}{*}{ Problems with latching } & Yes & 11 & $9.1 \%$ \\
\hline & & No & 109 & $90.9 \%$ \\
\hline \multirow{2}{*}{3} & \multirow{2}{*}{ Problems with sucking } & Yes & 10 & $8.4 \%$ \\
\hline & & No & 110 & $91.6 \%$ \\
\hline \multirow{2}{*}{4} & \multirow{2}{*}{ Breast problems } & Yes & 16 & $13.4 \%$ \\
\hline & & No & 104 & $86.6 \%$ \\
\hline \multirow{2}{*}{5} & \multirow{2}{*}{ Problems related to mother } & Yes & 46 & $38.3 \%$ \\
\hline & & No & 74 & $61.7 \%$ \\
\hline \multirow{2}{*}{6} & \multirow{2}{*}{ Difficulty in holding the baby } & Yes & 34 & $28.3 \%$ \\
\hline & & No & 86 & $71.7 \%$ \\
\hline \multirow{2}{*}{7} & \multirow{2}{*}{ Problems related to baby } & Yes & 9 & $7.5 \%$ \\
\hline & & No & 111 & $92.5 \%$ \\
\hline \multirow{2}{*}{8} & \multirow{2}{*}{ Giving other feeds } & Yes & 3 & $2.5 \%$ \\
\hline & & No & 117 & $97.5 \%$ \\
\hline
\end{tabular}

Many of these mothers were observed during feeding to confirm the problems whenever needed. Poor positioning and attachment were the predominant observed problems in breast-feeding (Table 3).

Table 3. Breastfeeding problems - observed (more than one response allowed)

\begin{tabular}{cccc}
\hline SI no. & Problems with feeding (observed) & Number of mothers & Percentage \\
\hline 1 & Nil & 79 & $65.8 \%$ \\
2 & Poor positioning & 36 & $30 \%$ \\
3 & Poor attachment & 18 & $15 \%$ \\
4 & Poor sucking & 8 & $6.7 \%$ \\
5 & Breast engorgement & 3 & $2.5 \%$ \\
6. & Inverted nipple & 2 & $1.6 \%$ \\
7. & Sore nipple & 1 & $0.8 \%$ \\
\hline
\end{tabular}

However, most of the problems were resolved before discharge a few persisted until discharge (Table 4). Poor positioning and attachment were still the prominent problems. The mothers and caregivers were further counselled regarding these issues.

Table 4. Breastfeeding problems - at discharge (more than one response allowed)

\begin{tabular}{cccc}
\hline Sl no. & Problems with feeding (observed) & Number of mothers & Percentage \\
\hline 1 & Nil & 100 & $83.3 \%$ \\
2 & Poor positioning & 11 & $9.1 \%$ \\
3 & Poor attachment & 7 & $5.8 \%$ \\
5 & Breastmilk inadequacy & 5 & $4.1 \%$ \\
6 & Problems with latching & 2 & $1.6 \%$ \\
7 & Breast engorgement & 1 & $0.8 \%$ \\
8. & Sore nipple & 1 & $0.8 \%$ \\
\hline
\end{tabular}

These breast-feeding problems were correlated with some important variables (Table 5). Perceived milk insufficiency, latching problems and breast problems were higher in primi and found to be statistically significant. Objective problems like poor positioning, sucking etc. were higher among primi and caesarean mothers. Even problems that remained at discharge were also more among them. 
Table 5. Correlation of breast feeding issues with selected variables

\begin{tabular}{|c|c|c|c|c|c|}
\hline \multicolumn{3}{|c|}{ Variables } & & \multirow{2}{*}{$\begin{array}{l}\text { Significance } \\
\text { Ifficiency }\end{array}$} & \multirow[t]{2}{*}{ OR (95\% C.I.) } \\
\hline \multicolumn{4}{|c|}{ Milk insufficiency } & & \\
\hline Parity & No & Yes & Total & \multirow{3}{*}{0.022} & \multirow{3}{*}{$\begin{array}{c}2.66 \\
(1.12,6.13)\end{array}$} \\
\hline Primi & 17 & 14 & 31 & & \\
\hline Multi & 68 & 21 & 89 & & \\
\hline \multicolumn{6}{|c|}{ Latching problems } \\
\hline Parity & No & Yes & Total & \multirow{3}{*}{0.02} & \multirow{3}{*}{$\begin{array}{c}5.51 \\
(1.23,24.63)\end{array}$} \\
\hline Primi & 26 & 5 & 31 & & \\
\hline Multi & 86 & 3 & 89 & & \\
\hline \multicolumn{6}{|c|}{ Breast problems } \\
\hline Parity & No & Yes & Total & \multirow{3}{*}{0.004} & \multirow{3}{*}{$\begin{array}{c}5.84 \\
(1.74,19.57)\end{array}$} \\
\hline Primi & 23 & 8 & 31 & & \\
\hline Multi & 84 & 5 & 89 & & \\
\hline \multicolumn{6}{|c|}{ Objective problems } \\
\hline Parity & No & Yes & Total & & \\
\hline Primi & 16 & 15 & 31 & \multirow[t]{2}{*}{0.052} & \multirow{2}{*}{$\begin{array}{c}2.27 \\
(0.98,5.25)\end{array}$} \\
\hline Multi & 63 & 26 & 89 & & \\
\hline \multicolumn{4}{|c|}{ Mode of delivery } & \multirow{3}{*}{$<0.001$} & \multirow{3}{*}{$\begin{array}{c}4.65 \\
(2.05,10.54)\end{array}$} \\
\hline Caesarean & 27 & 29 & 56 & & \\
\hline Vaginal & 52 & 12 & 64 & & \\
\hline \multicolumn{4}{|l|}{ Age group } & \multirow{5}{*}{0.012} & \\
\hline$<25 \mathrm{yr}$. & 20 & 21 & 41 & & \\
\hline $26-30 \mathrm{yr}$. & 19 & 45 & 64 & & \\
\hline $31-35 \mathrm{yr}$. & 0 & 12 & 12 & & \\
\hline$>35 \mathrm{yr}$. & 1 & 2 & 3 & & \\
\hline \multicolumn{6}{|c|}{ Problems at discharge } \\
\hline Parity & No & Yes & Total & & \\
\hline Primi & 21 & 10 & 31 & \multirow{2}{*}{0.006} & \multirow{2}{*}{$\begin{array}{c}3.76 \\
(1.38,10.22)\end{array}$} \\
\hline Multi & 79 & 10 & 89 & & \\
\hline \multicolumn{6}{|c|}{ Mode of delivery } \\
\hline Caesarean & 42 & 14 & 56 & \multirow{2}{*}{0.021} & \multirow{2}{*}{$\begin{array}{c}3.22 \\
(1.14,9.07)\end{array}$} \\
\hline Vaginal & 58 & 6 & 64 & & \\
\hline
\end{tabular}

\section{Discussion}

This study shows breast feeding issues in early postnatal days i.e. until discharge from hospital. Most of our study group mothers were educated and had some information about breast-feeding, yet they were of the opinion that breast feeding education is needed. We can increase breast-feeding education at primary health care center level during antenatal visits with pamphlets and posters. Surprisingly a study done by Bernard Asare et al. [4] in Ghana found that young mothers and those with no education were more likely to practice exclusive breast feeding as compared to those with higher education. This was explained by the fact that in Ghana mothers with higher education tend to engage in formal employment, hindering exclusive breast-feeding. Another study observed that women who have information were 2 times more likely to exclusively breast feed than those who have no information [5].

We divided the feeding problems as reported and observed. An All India Institute of Medical sciences study had more reported as well as observed problems. This may be attributed to the difference in sample size and other demographic variations [6].

Difficulty in holding the baby and insufficiency of milk were the predominantly reported problems. A study by Yogendra Prasad et al. [7] showed that there is a lack of knowledge regarding breast-feeding and problems ranged from how to hold the baby (16.5\%), mother believing that milk was insufficient (13\%) and refusal of baby to suckle $(8.7 \%)$. A study done in Iraq showed similar results with proper positioning and latching only in $27.5 \%$ and refusal of 
baby to breast feed in $21.9 \%$ and mother believing that she has inadequate milk in $19.5 \%$ [8].

A study done in Mysore city in India by Singh et al. [9] showed a gap between actual and desired practices, emphasizing the need for intervention programs during antenatal and postnatal checkups. A study conducted in Nigeria showed that nearly $58 \%$ primi mothers had lack of knowledge regarding exclusive breast-feeding and only around $62 \%$ intended to exclusively breast-feed their babies [10].

Insufficiency of milk was reported in $29 \%$ of our subjects. Although most women are capable of producing enough milk as per the baby's requirement, many mothers perceive that their milk supply is inadequate. Counseling again has a major role here, or else this will lead to early initiation of formula feeds or weaning. Even in a Chinese study, $37.1 \%$ perceived insufficient milk. The misinterpretation of insufficient milk and caregiver's attitude towards breast-feeding are important factors for breast feeding efficacy [11]

A study in New Delhi showed very high number of breast feeding problems $(88.5 \%)$. They noticed sore/ cracked nipple in $17.8 \%$, retracted/ flat nipple in $15 \%$ and breast engorgement in $13 \%$. Major problem was with positioning. In our study, these problems were observed in very few mothers. This may be related to the education level of the mothers as well as early discharge in our cases. Nipple pain, perceived low milk supply are known to negatively affect breast-feeding. Even an Australian study reinforced that these were important issues experienced by a significant number of women in the community $[12,13]$.

We found to have higher feeding problems in primi mothers and those delivered by caesarean, which may be due to apprehension (first time) and post-surgery pain and fear, emphasizing the need to focus on these high risk groups in teaching breast feeding practices as part of postnatal care. Feenstra et al. [14] noted early breast feeding problems in up to $40 \%$ of the mothers. Most important ones were inability to latch on (40\%) and sore cracked nipples (38\%). Primiparity and lower knowledge of breast-feeding were associated with problems. There is an interesting article published recently in breast feeding journal about the experiences of 22 mothers regarding breast feeding [15].

Some of these problems persisted even at the time of discharge who were again counselled and advised for early follow-ups. Longer follow-ups of every mother would have helped in assessing exclusive breast-feeding rate and persistence of feeding problems. A systematic review based on $>30$ articles showed that women experienced many problems with breast-feeding and prenatal health education counselling helped in reducing the problems [16]. WHO and UNICEF recommend the use of a sucking evaluation file to identify initial difficulties involving breast feeding techniques [17].

\section{Conclusion}

The importance of breast-feeding cannot be neglected. There is a large burden of breast feeding problems in mothers. The success in breast-feeding is dependent on early initiation and effective management of breast feeding problems during early postnatal days. There is a need for increasing health education regarding breast-feeding during antenatal period. Most common problems were positioning, emphasizing the need for teaching/training. Primi and delivery by caesarean were found to have higher feeding problems emphasizing the need to focus on these high risk groups.

\section{Acknowledgements}

We gratefully acknowledge all the participants who participated in this study.

\section{Declaration of Competing Interest}

The authors declare that they have no known competing financial interests or personal relationships that could have appeared to influence the work reported in this paper.

\section{Ethical Approval}

Participants gave their written consent to use their anonymous data for statistical purposes. All of them were over 18 years old and voluntarily collaborated without receiving any financial compensation. The procedures were carried out in compliance with the institutional regulations of the Institutional Ethics Committee (IEC) | Public Health Foundation of India. Similarly, all procedures adhere to the Helsinki Declaration of 1964, revised in 2013.

\section{References}

[1]Parks EP, Shaikh Khalil A, Grolean V, Wendel D, Stallings VA. (2016) . Feeding healthy infants, children and adolescents. In: Nelson Text book of Paediatrics 20 e, Kliegmenn, Stanton, St Geme, Schor editors, Reed Elsevier, India PVT Ltd, New Delhi, 286-295. 
[2] Kishore, M. S. S., Kumar, P., \& Aggarwal, A. K. (2008). Breastfeeding Knowledge and Practices amongst Mothers in a Rural Population of North India: A Community-based Study. Journal of Tropical Pediatrics, 55(3), $183-188$. doi:10.1093/tropej/fmn110.

[3] Breast feeding Lancet series (2016): India's road map 2016: Breastfeeding promotion network of India p5. Available online: http://www.thelancet.com/series/breastfeeding (accessed on 30 March 2020).

[4] Asare, B. Y.-A., Preko, J. V., Baafi, D., \& Dwumfour-Asare, B. (2018). Breastfeeding practices and determinants of exclusive breastfeeding in a cross-sectional study at a child welfare clinic in Tema Manhean, Ghana. International Breastfeeding Journal, 13(1). doi:10.1186/s13006-018-0156-y.

[5] Mulatu Dibisa, T., \& Sintayehu, Y. (2020). Exclusive Breast Feeding and Its Associated Factors Among Mothers of $<12$ Months Old Child in Harar Town, Eastern Ethiopia: A Cross-Sectional Study. Pediatric Health, Medicine and Therapeutics, Volume 11, 145-152. doi:10.2147/phmt.s253974.

[6] Raju, J., Vatsa, M., \& Agarwal, R. K. (2011). Breastfeeding Problems during First Three Postnatal Days. Pediatric Research, 70, 824-824. doi:10.1038/pr.2011.1049.

[7] R., Y. P., P., C., \& G., M. (2017). Common breast feeding problems in mothers in early postnatal period. International Journal of Contemporary Pediatrics, 4(2), 625. doi:10.18203/2349-3291.ijcp20170721.

[8] Najem, B. (2011). Breast Feeding Problems in Primipara Mothers in Early Postnatal Period. Iraqi Journal of Community Medicine, 24(3), 192-195.

[9] Singh, J., Vishakantamurthy, D., \& Charan, P. (2012). Breastfeeding practices among lactating mothers: Problems and prospects in a cross-sectional study. International Journal of Health \& Allied Sciences, 1(2), 54. doi:10.4103/2278-344x.101663.

[10] Ihudiebube-Splendor, C. N., Okafor, C. B., Anarado, A. N., Jisieike-Onuigbo, N. N., Chinweuba, A. U., Nwaneri, A. C., ... Chikeme, P. C. (2019). Exclusive Breastfeeding Knowledge, Intention to Practice and Predictors among Primiparous Women in Enugu South-East, Nigeria. Journal of Pregnancy, 2019, 1-8. doi:10.1155/2019/9832075.

[11] Li, T., Guo, N., Jiang, H., \& Eldadah, M. (2018). Breastfeeding Self-Efficacy among Parturient Women in Shanghai: A CrossSectional Study. Journal of Human Lactation, 35(3), 583-591. doi:10.1177/0890334418812044.

[12] Sharma, K., Saksena, M., Thukral, A., Vatsa, M., Agarwal, R., \& Suresh, S. (2014). Predictors of breastfeeding problems in the first postnatal week and its effect on exclusive breastfeeding rate at six months: experience in a tertiary care centre in Northern India. Indian Journal of Public Health, 58(4), 270. doi:10.4103/0019-557x.146292.

[13] Ridgway, L., Cramer, R., McLachlan, H. L., Forster, D. A., Cullinane, M., Shafiei, T., \& Amir, L. H. (2016). Breastfeeding Support in the Early Postpartum: Content of Home Visits in the SILC Trial. Birth, 43(4), 303-312. doi:10.1111/birt.12241.

[14] Feenstra, M. M., Jørgine Kirkeby, M., Thygesen, M., Danbjørg, D. B., \& Kronborg, H. (2018). Early breastfeeding problems: A mixed method study of mothers' experiences. Sexual \& Reproductive Healthcare, 16, 167-174. doi:10.1016/j.srhc.2018.04.003.

[15] Xiao, X., Loke, A. Y., Zhu, S., Gong, L., Shi, H., \& Ngai, F. (2020). "The sweet and the bitter”: mothers' experiences of breastfeeding in the early postpartum period: a qualitative exploratory study in China. International Breastfeeding Journal, 15(1). doi:10.1186/s13006-020-00256-1.

[16] Karacam, Z., \& Saglik, M. (2018). Breastfeeding problems and interventions performed on problems: systematic review based on studies made in Turkey. Türk Pediatri Arşivi, 53(3), 134-148. doi:10.5152/turkpediatriars.2018.6350.

[17] Barbosa, G. E. F., Silva, V. B. da, Pereira, J. M., Soares, M. S., Medeiros Filho, R. dos A., Pereira, L. B., ... Caldeira, A. P. (2017). Dificuldades Iniciais Com A Técnica Da Amamentação E Fatores Associados A Problemas Com A Mama Em Puérperas. Revista Paulista de Pediatria, 35(3), 265-272. doi:10.1590/1984-0462/;2017;35;3;00004. 